\title{
Quality of care and patient safety at healthcare institutions in Oman: quantitative study of the perspectives of patients and healthcare professionals
}

\author{
Fatma Al-Jabri ${ }^{1 *}$, Tarja Kvist ${ }^{1}$, Reijo Sund ${ }^{2}$ and Hannele Turunen ${ }^{1}$
}

\begin{abstract}
Background: Oman's healthcare system has rapidly transformed in recent years. A recent Report of Quality and Patient Safety has nevertheless highlighted decreasing levels of patient safety and quality culture among healthcare professionals. This indicates the need to assess the quality of care and patient safety from the perspectives of both patients and healthcare professionals.

Objectives: This study aimed to examine (1) patients' and healthcare professionals' perspectives on overall quality of care and patient safety standards at two tertiary hospitals in Oman and (2) which demographic characteristics are related to the overall quality of care and patient safety.

Methods: A cross-sectional study design was employed. Data were collected by two items: overall quality of care and patient safety, incorporated in the Revised Humane Caring Scale, and Healthcare Professional Core Competency Instrument. Questionnaires were distributed to (1) patients $(n=600)$ and (2) healthcare professionals (nurses and physicians) $(n=246)$ in three departments (medical, surgical and obstetrics and gynaecology) at two tertiary hospitals in Oman towards the end of 2018 and the beginning of 2019. Descriptive statistics and binary logistic regression were used for data analysis.

Results: A total of 367 patients and 140 healthcare professionals completed the questionnaires, representing response rates of $61.2 \%$ and $56.9 \%$, respectively. Overall, quality of care and patient safety were perceived as high, with the healthcare professionals rating quality of care $(M=4.36 ; S D=0.720)$ and patient safety $(M=4.39 ; S D=$ $0.675)$ slightly higher than the patients did $(M=4.23 ; S D=0.706),(M=4.22 ; S D=0.709)$. The findings indicated an association between hospital variables and overall quality of care $(\mathrm{OR}=0.095 ; 95 \% \mathrm{Cl}=0.016-0.551 ; p=0.009)$ and patient safety $(\mathrm{OR}=0.153 ; 95 \% \mathrm{Cl}=0.027-0.854 ; p=0.032)$ among healthcare professionals. Additionally, an association between the admission/work area and participants' perspectives on the quality of care (patients, $\mathrm{OR}=$ $0.257 ; 95 \% \mathrm{Cl}=0.072-0.916 ; p=0.036$; professionals, $\mathrm{OR}=0.093 ; 95 \% \mathrm{Cl}=0.009-0.959 ; p=0.046$ ) was found.
\end{abstract}

\footnotetext{
*Correspondence: fatma@uef.fi

'Department of Nursing Science, University of Eastern Finland, P.O. Box 1627,

70211 Kuopio, Finland

Full list of author information is available at the end of the article
}

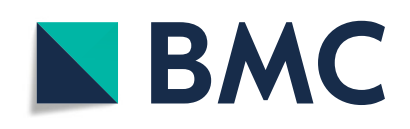

(c) The Author(s). 2021 Open Access This article is licensed under a Creative Commons Attribution 4.0 International License, which permits use, sharing, adaptation, distribution and reproduction in any medium or format, as long as you give appropriate credit to the original author(s) and the source, provide a link to the Creative Commons licence, and indicate if changes were made. The images or other third party material in this article are included in the article's Creative Commons licence, unless indicated otherwise in a credit line to the material. If material is not included in the article's Creative Commons licence and your intended use is not permitted by statutory regulation or exceeds the permitted use, you will need to obtain permission directly from the copyright holder. To view a copy of this licence, visit http://creativecommons.org/licenses/by/4.0/ The Creative Commons Public Domain Dedication waiver (http://creativecommons.org/publicdomain/zero/1.0/) applies to the data made available in this article, unless otherwise stated in a credit line to the data. 
Conclusions: The perspectives of both patients and healthcare professionals showed that they viewed both quality of care and patient safety as excellent, with slight differences, indicating a high level of patient satisfaction and competent healthcare delivery professionals. Such perspectives can provide meaningful and complementary insights on improving the overall standards of healthcare delivery systems.

Keywords: Patients' perspectives, Healthcare professionals' perspectives, Quality of care, Patient safety, Quantitative study, Oman

\section{Background}

Quality of care and patient safety are undoubtedly two distinctive targets for leading healthcare systems around the world [1-3]. These targets continue to be at the top of the agenda for healthcare regulators and policy markers in the Sultanate of Oman [4]. Oman's Ministry of Health $(\mathrm{MOH})$ established the Department of Quality and Patient Safety in regional hospitals in 2007 to implement a quality assurance strategy [5]. It also adopted the Patient Safety Friendly Hospital Initiative (PSFHI) in 2015 to promote an inclusive and integrative healthcare system [6]. Such efforts have considerably improved the outcomes of the healthcare system, for instance, by drastically reducing mortality rates of children under five by $72 \%$ from 1990 to 2013 and maternal mortality rates by 55\% from 1990 to 2013 [5, 7].

Although Oman's healthcare system was ranked by the World Health Organization (WHO) as one of the10 best healthcare systems in the world in 2012 [8], a recent Report of Quality and Patient Safety (RQPS) highlighted a decreased level of patient safety and quality of care culture among healthcare professionals (HCPs) [9]. The report called for a comprehensive assessment of quality of care and patient safety to include the perspectives of both HCPs (as service providers) and patients (as service users). The report recognizes that HCPs typically focus on longterm and sustainable solutions while managing service and delivery costs [10]. Their core competencies and wider technical excellence - often play a pivotal role in the overall classification of quality of care and patient safety from the perspective of healthcare providers [3, 11-13].

On the other hand, patients tend to value short-term comforts [14]. Their perspectives are usually based on the overall healthcare system, practice type, and care providers' personal and clinical skills $[13,15,16]$. This explains why world organizations such as the Council of Europe (CoE) [17], the WHO [3], and the United States (US) Institute of Medicine (IOM) [18] all enhance that patients' views of quality care are important in addition to providers' views to find the right balance between two perspectives and provide additional insight into areas where change is needed. Therefore, this study is part of a larger study that aims to (1) consolidate patients' and
HCPs' (nurses and physicians) perspectives on quality of care and patient safety at two tertiary hospitals in Oman [19] and (2) identify the participant characteristics most related to quality of care and patient safety. The outcomes of this study will provide meaningful and complementary insights for improving the overall standards of healthcare delivery systems.

\section{Methods \\ Study context}

This study was conducted in Oman, a high-income Arab country of 4.6 million people; one- third of its population lives in the capital city of Oman [20]. It has experienced rapid economic and social transformation since 1970, which has resulted in better quality living standards. By 2019, Oman's MOH had a total of 50 hospitals; 5049 beds; 269 health centres, clinics, and dispensaries (governmental); and 1254 private clinics. The total numbers of doctors and nurses were 6419 and 14,491 , respectively. In 2019 , for every 10,000 people, there were 21 doctors and 44 nurses in the country, and the nurse-doctor ratio was 2:1. The healthcare system in Oman is characterised by its universal coverage for both citizens and expatriates and its health system comprises both the government and private sectors. Healthcare is provided in facilities mainly owned and run by the government, which covers approximately $81.1 \%$ of the total health expenditure (THE), providing $83.1 \%$ of the hospitals, $92.5 \%$ of the hospital beds, $62.2 \%$ of all outpatient services, and $94.5 \%$ of all inpatient services [21].

\section{Design}

A cross-sectional design was used to conduct the study. Study reporting followed the STrengthening the Reporting of OBservational studies in Epidemiology (STROBE) guidelines [22] (see Additional file 1).

\section{Sample and setting}

This study targeted (1) adult patients and (2) all HCPs (nurses and physicians) from three departments (medical, surgical, and obstetrics and gynaecology (OBG)) at two tertiary hospitals (namely, hospitals A and B) in Oman. Data were collected over a one-month period towards the end of 2018 and the beginning of 2019. The necessary sample size for patients was estimated by 
power analysis, which indicated that at least 313 respondents were required for hospital ' $A$ ' and 158 for hospital ' $B$ ', where the effect size $(d=0.5), \alpha=0.05$ and $N$ was 6155 (4094 from hospital 'A' and 2061 from hospital 'B') discharged patients at two hospitals [21]. Patient data were collected through convenience sampling of 600 adult patients admitted to hospitals A and B (400 and 200 , respectively). To minimize potential bias from convenience sampling, the authors enrolled more participants than the minimum required sampling size and maximized the participant follow-up and reminders.

The sample size for HCPs was taken from the primary study data that covered all of Oman, and HCPs were recruited though proportional stratified sampling of 246 professionals (139 nurses and 107 physicians) who worked at the two hospitals.

\section{Study instruments}

Data for this study were collected by two items: overall quality of care and patient safety incorporated in the Revised Humane Caring Scale (RHCS) and the Healthcare Professional Core Competency Instrument (HPCCI) for patients and HCPs, respectively [23-25]. The above two items were developed by the authors and piloted as a part of the larger study with the entire RHCS and HPCCI instruments through convenience sampling of patients $(n=30)$ and HCPs $(n=56)$ at tertiary hospital in Oman. The HPCCI, that consists of 11 subscales with 81 items, was adopted from existing valid and reliable tools, and permission to use the tools was granted by their developers. The RHCS, that comprises of seven subscales with 46 items and two more items were added in this study in Oman, has been translated by experts from English to the Arabic language and backwards to English. Based on the pilot, there were no changes required to the tool. A 5-point Likert scale ( $1=$ Failing, 2 = Poor, 3 = Acceptable, $4=$ Very Good, $5=$ Excellent) was used to rate the two items in the questionnaires distributed to the patients and the HCPs. The minimum score of 1 was considered to indicate failing perceptions on quality of care and patient safety while the maximum score of 5 was signifying excellent levels.

\section{Data collection}

The principal researcher worked closely with the research assistants from the two target hospitals and explained the scope of the study and data collection process. The research assistants were given a number of questionnaires along with fact sheets; the questionnaires were distributed to both target groups: patients and HCPs, over a period of 1 month. The completed questionnaires were inserted into envelopes in locked boxes allocated to each unit. During the study period, a verbal reminder was delivered by the researcher assistants in both institutions to the target groups. The participants had the right to withdraw from the study.

\section{Ethical approval}

Ethical approval to conduct the study was granted by the University Committee on Research Ethics (Statement $16 / 2018)$, and permission to conduct the study in the hospitals was obtained from the $\mathrm{MOH}$, Sultanate of Oman (Proposal ID: MOH/CSR/18/XXXX). This study used data collected in December 2018 and January 2019. The anonymity of the participants was guaranteed, and all data were treated confidentially.

\section{Data analysis}

Data were analysed using descriptive statistics (frequency, percentage, mean value, and standard deviation). The statistical mean was the parameter that was used to measure the overall quality of care and patient safety. A mean score of 1 indicated the lowest score, while a mean score of 5 was considered the highest. On this scale range, a mean value of 4 or more was considered 'excellent'. This value reflects the best practices as per the literature and magnet hospital assessment scales, where 4 is defined as meeting the Magnet standards [26]. Binary logistic regression analysis was performed to determine the associations between the dependent variables (overall quality of care and patient safety) and independent variables (demographic characteristics) for both patients and HCPs. The quality of care and patient safety variables were dichotomized as combined; 'excellent or very good' was recorded as 1, and 'acceptable, poor, and failing' was recorded as 0 . In this analysis, the $P$ value $(P)$, odds ratio (OR), and 95\% confidence interval (CI) of the OR were calculated to understand how the predictors were associated with the outcomes. Multivariate and univariate analyses were performed. Data were analysed using the Statistical Package for the Social Sciences computer program (SPSS version 27.0).

\section{Results \\ Participants' demographic characteristics}

The overall response rate for patients was $61.2 \%$ (367 of 600 targets); it corresponded to 218 patients (59.4\%) from hospital A and 149 (40.6\%) from hospital B. In the case of HCPs, the overall response rate was $56.9 \%$ (140 of 246 targets); there were 65 professionals (46.4\%) from hospital A and 75 (53.6\%) from hospital B (Table 1). Less than $30 \%$ of the patients and more than $50 \%$ of the staff fell within the group of individuals 30-40 years of age. Most of the patients and professionals were women: 58.5 and $75.5 \%$, respectively. Most of the patients were Omani citizens (93\%), and the response rate of Omani staff was slightly higher (3.6\%) than that of expatriates. 
Table 1 Participants' demographic characteristics

\begin{tabular}{|c|c|c|c|c|c|c|c|}
\hline \multicolumn{4}{|l|}{ Patients } & \multicolumn{4}{|c|}{ Healthcare Professionals } \\
\hline & & $\mathrm{n}$ & $\%$ & & & $\mathrm{n}$ & $\%$ \\
\hline \multirow[t]{4}{*}{ Hospital } & $A$ & 218 & 59.4 & Hospital & A & 65 & 46.4 \\
\hline & B & 149 & 40.6 & & B & 75 & 53.6 \\
\hline & & & & Profession & Nurse & 84 & 60.0 \\
\hline & & & & & Physician & 56 & 40.0 \\
\hline \multirow[t]{3}{*}{ Age in (years) } & $<30$ & 119 & 35.6 & Age in (years) & $<30$ & 28 & 24.6 \\
\hline & $30-40$ & 94 & 28.1 & & $30-40$ & 59 & 51.8 \\
\hline & $>40$ & 121 & 36.2 & & $>40$ & 27 & 23.7 \\
\hline \multirow[t]{2}{*}{ Gender } & Female & 210 & 58.5 & Gender & Female & 105 & 75.5 \\
\hline & Male & 149 & 41.5 & & Male & 34 & 24.5 \\
\hline \multirow[t]{2}{*}{ Ethnicity } & Omani & 332 & 93.0 & Ethnicity & Omani & 72 & 51.8 \\
\hline & Non-Omani & 25 & 7.0 & & Non-Omani & 67 & 48.2 \\
\hline \multirow[t]{2}{*}{ Living } & Alone & 39 & 11.3 & Position & Clinician & 84 & 78.5 \\
\hline & With family & 305 & 88.7 & & Management & 4 & 3.7 \\
\hline \multirow[t]{2}{*}{ Education } & Post-secondary school education & 140 & 40.0 & & Both & 19 & 17.8 \\
\hline & Basic level of education & 210 & 60.0 & Work experience & $<8$ years & 41 & 34.2 \\
\hline \multirow[t]{6}{*}{ Occupational status } & Un-employed & 154 & 43.9 & & $8-15$ years & 44 & 36.7 \\
\hline & Employed & 159 & 45.3 & & $>15$ year & 35 & 29.2 \\
\hline & Retiree & 38 & 10.8 & Education & Diploma/resident & $60 / 13$ & $71.4 / 27.1$ \\
\hline & & & & & Bachelor/specialist & $23 / 34$ & $27.4 / 70.8$ \\
\hline & & & & & Master/adjunct & $1 / 0$ & $1.2 / 0$ \\
\hline & & & & & Ph.D./docent & $0 / 1$ & $0 / 2.1$ \\
\hline \multirow[t]{3}{*}{ Admission area } & Medical & 117 & 34.7 & Work area & Medical & 34 & 25.0 \\
\hline & Surgical & 156 & 46.3 & & Surgical & 71 & 52.2 \\
\hline & Obstetrics and gynaecology & 64 & 19.0 & & Obstetrics and gynaecology & 31 & 22.8 \\
\hline \multirow[t]{2}{*}{ Hospital admission } & Planned & 132 & 37.7 & & & & \\
\hline & Emergency & 218 & 62.3 & & & & \\
\hline \multirow[t]{2}{*}{ Reason of admission } & Examination & 47 & 13.3 & & & & \\
\hline & Treatment & 306 & 86.7 & & & & \\
\hline \multirow[t]{2}{*}{ Stay duration } & $<=5$ Days & 192 & 67.6 & & & & \\
\hline & $>5$ Days & 92 & 32.4 & & & & \\
\hline
\end{tabular}

Approximately $89 \%$ of the patients lived with their families and $60 \%$ had a basic level of education. Approximately $45 \%$ of them were employed and $44 \%$ were unemployed. Approximately $78.5 \%$ of the HCPs worked at the bedside, followed by those who had dual roles, that is, clinical and management work. There were several similarities among respondents from each working group of HCPs. Approximately two-thirds of them had between 8 and 15 years of work experience. The majority of nurses and physicians had diplomas (71.4\%) and specializations (70.8\%) as their educational background/ qualifications.

Approximately half of the patients (46.3\%) and HCPs (52.2\%) were from the surgical department, followed by those from the medical department. Almost two-thirds of the patients were emergency-admitted cases (62.3\%) and sought treatment rather than examination (87\%). Two-thirds of the patients (67.6\%) spent less than 5 days in the hospital.

\section{Participants' perspectives on quality of care and patient safety}

Table 2 presents the participants' perspectives on the quality of care and patient safety standards. Overall, quality of care (patients: $\mathrm{M}=4.23 ; \mathrm{SD}=0.706 ; \mathrm{HCPs}$ : $\mathrm{M}=4.36 ; \mathrm{SD}=0.720$ ) and patient safety (patients: $\mathrm{M}=$ 4.22; $\mathrm{SD}=0.709$; HCPs: $\mathrm{M}=4.39 ; \mathrm{SD}=0.675$ ) were rated as excellent from both perspectives. However, the 
Table 2 Participants' perspectives on quality of care and patient safety

\begin{tabular}{|c|c|c|c|c|c|c|c|c|c|c|c|c|c|c|}
\hline \multirow{3}{*}{$\begin{array}{l}\text { Participants } \\
\text { Patients }\end{array}$} & \multicolumn{7}{|c|}{ Overall quality of care } & \multicolumn{7}{|c|}{ Overall patient safety } \\
\hline & \multirow{2}{*}{$\frac{\mathbf{N}}{348}$} & \multirow{2}{*}{$\frac{\mathbf{M}}{4.23}$} & \multirow{2}{*}{$\frac{\text { SD }}{0.706}$} & \multirow{2}{*}{$\begin{array}{l}\text { SE } \\
0.038\end{array}$} & \multirow{2}{*}{$\begin{array}{l}\mathbf{P} \\
0.068\end{array}$} & \multicolumn{2}{|c|}{$95 \% \mathrm{Cl}$} & \multirow{2}{*}{$\frac{\mathbf{N}}{351}$} & \multirow{2}{*}{$\frac{\mathbf{M}}{4.22}$} & \multirow{2}{*}{$\frac{S D}{0.709}$} & \multirow{2}{*}{$\begin{array}{l}\text { SE } \\
0.038\end{array}$} & \multirow{2}{*}{$\begin{array}{l}\mathbf{P} \\
0.013\end{array}$} & \multicolumn{2}{|c|}{$95 \% \mathrm{Cl}$} \\
\hline & & & & & & 4.16 & 4.30 & & & & & & 4.15 & 4.29 \\
\hline HCPs & 140 & 4.36 & 0.720 & 0.061 & & 4.24 & 4.48 & 140 & 4.39 & 0.675 & 0.057 & & 4.28 & 4.50 \\
\hline Total & 488 & 4.26 & 0.712 & 0.032 & & 4.20 & 4.33 & 491 & 4.27 & 0.704 & 0.032 & & 4.21 & 4.33 \\
\hline
\end{tabular}

$N$ Number of participants, $M$ Mean, SD Standard deviation, SE Standard error, $P P$ value, $C I$ Confidence interval

participants differed significantly in their views of patient safety $(p=0.013)$.

\section{Association between demographic characteristics and overall quality of care and patient safety}

A binary logistic regression analysis was performed to ascertain the association of hospital, age, gender, ethnicity, and admission/work area on the overall quality of care and patient safety. These specific variables were chosen as they feature in both instruments (RHCS and HPCCI), and a subsequent comparison can be made. Table 3 shows that patients at hospital A (OR 0.622; 95\% CI 0.271-1.424; $p=$ 0.261 ) were less satisfied with quality of care than those at hospital B, but the finding was not statistically significant. HCPs at hospital A (OR 0.095; 95\% CI 0.016-0.551; $p=$ 0.009 ) were $90 \%$ less satisfied than those at hospital B with regard to quality of care. There was also a nonsignificant tendency for men (OR 1.920; 95\% CI 0.972-3.792; $p=$ $0.060)$ to rate quality of care higher than women did. The results showed a tendency for less satisfaction with quality of care in the medical department than in the OBG department among patients $(p=0.036)$ as well as $\operatorname{HCPs}(p=$ 0.046).

Table 4 shows the results of the binary logistic regression analysis performed to assess whether demographic characteristics of patients and HCPs explain the overall

Table 3 Binary logistic regression analysis of the quality of care

\begin{tabular}{|c|c|c|c|c|c|c|c|c|}
\hline \multirow{3}{*}{ Hospital } & \multicolumn{4}{|c|}{ Patients } & \multicolumn{4}{|c|}{ Healthcare professionals } \\
\hline & \multirow[t]{2}{*}{$O R^{a}$} & \multicolumn{2}{|l|}{$C I^{b}$ of $O R$} & \multirow[t]{2}{*}{$P^{c}$} & \multirow[t]{2}{*}{$O R^{a}$} & \multicolumn{2}{|c|}{$\mathrm{Cl}^{b}$ of $\mathrm{OR}$} & \multirow[t]{2}{*}{$P^{c}$} \\
\hline & & & & & & & & \\
\hline A & 0.622 & 0.271 & 1.424 & 0.261 & 0.095 & 0.016 & 0.551 & 0.009 \\
\hline B & 1 & Ref. & & & 1 & Ref. & & \\
\hline \multicolumn{9}{|l|}{ Age in (years) } \\
\hline$<30$ & 0.860 & 0.408 & 1.813 & 0.692 & 0.131 & 0.010 & 1.707 & 0.121 \\
\hline $30-40$ & 1.901 & 0.755 & 4.791 & 0.173 & 0.148 & 0.014 & 1.606 & 0.116 \\
\hline$>40$ & 1 & Ref. & & 0.223 & 1 & Ref. & & 0.269 \\
\hline \multicolumn{9}{|l|}{ Gender } \\
\hline Male & 1.920 & 0.972 & 3.792 & 0.060 & 1.496 & 0.255 & 8.790 & 0.656 \\
\hline Female & 1 & Ref. & & & 1 & Ref. & & \\
\hline \multicolumn{9}{|l|}{ Ethnicity } \\
\hline Omani & 0.571 & 0.166 & 1.967 & 0.375 & 1.941 & 0.420 & 8.962 & 0.396 \\
\hline Non-Omani & 1 & Ref. & & & 1 & Ref. & & \\
\hline \multicolumn{9}{|l|}{ Admission/Work area } \\
\hline Medical & 0.257 & 0.072 & 0.916 & 0.036 & 0.093 & 0.009 & 0.959 & 0.046 \\
\hline Surgical & 0.376 & 0.115 & 1.227 & 0.105 & 0.103 & 0.011 & 0.999 & 0.050 \\
\hline Obstetrics and gynaecology & 1 & Ref. & & 0.110 & 1 & Ref. & & 0.119 \\
\hline Classification percentage correct & $83.3 \%$ & & & & $84.5 \%$ & & & \\
\hline 2 Log likelihood & $241.401^{a}$ & & & & $72.160^{\mathrm{a}}$ & & & \\
\hline Cox \& Snell R Square & .076 & & & & .185 & & & \\
\hline Nagelkerke R Square & .128 & & & & .321 & & & \\
\hline Hosmer and Lemeshow & 0.528 & & & & 0.338 & & & \\
\hline
\end{tabular}

${ }^{a}$ Odds ratio

${ }^{b} 95 \%$ confidence interval of odds ratio

${ }^{c} P$ value (level of significance) 
perceptions of patient safety standards as good as excellent. There were no statistically significant differences between patients' perspectives on patient safety standards at either hospital; however, patients in hospital A (OR 0.659; 95\% CI 0.298-1.457; $p=0.303$ ) were less satisfied than those in hospital B. Additionally, HCPs at hospital A (OR 0.153; 95\% CI 0.027-0.854; $p=0.032$ ) were $85 \%$ less satisfied with patient safety standards than HCPs at hospital B. There was also a nonsignificant tendency for men (OR 1.856; 95\% CI 0.955-3.606; $p=$ 0.068 ) to give better scores for patient safety standards than women. The results revealed a tendency for patients to be less satisfied with safety in the medical department than in the OBG department $(p=0.066)$.

\section{Discussion}

This study had two aims: first, to examine both patients' and HCPs' perspectives on overall quality of care and patient safety standards at two tertiary hospitals in Oman and, second, to examine the association of demographic characteristics with the overall quality of care and patient safety. The main findings of this study indicated that quality of care and patient safety were rated relatively high, indicating competent healthcare delivery professionals and a high level of patient satisfaction.

\section{Perspectives on overall quality of care and patient safety}

The preceding results demonstrate that patients ranked both quality of care and patient safety as excellent (4.22 and 4.23 , respectively). This indicates that patients acknowledged and appreciated the healthcare services provided to them by the HCPs. This not only increases their level of satisfaction and trust in the healthcare system but may also increase their tendency to agree to treatment plans and procedures. Such a perspective may in turn help expedite patient recovery and increase the total value delivered per medical resource and intervention [27].

HCPs also ranked both quality of care and patient safety as excellent (4.39 and 4.36, respectively). This may reflect that HCPs see themselves as skilled professionals who are well-rounded in core competencies, who implement the quality assurance strategy, and who put into

Table 4 Binary logistic regression analysis of patient safety

\begin{tabular}{|c|c|c|c|c|c|c|c|c|}
\hline \multirow{3}{*}{ Hospital } & \multicolumn{4}{|c|}{ Patients } & \multicolumn{4}{|c|}{ Healthcare professionals } \\
\hline & \multirow[t]{2}{*}{$O R^{a}$} & \multicolumn{2}{|l|}{$C I^{b}$ of $O R$} & \multirow[t]{2}{*}{$P^{c}$} & \multirow[t]{2}{*}{$O R^{a}$} & \multicolumn{2}{|c|}{$\mathrm{Cl}^{b}$ of $\mathrm{OR}$} & \multirow[t]{2}{*}{$P^{c}$} \\
\hline & & & & & & & & \\
\hline A & 0.659 & 0.298 & 1.457 & 0.303 & 0.153 & 0.027 & 0.854 & 0.032 \\
\hline B & 1 & Ref. & & & 1 & Ref. & & \\
\hline \multicolumn{9}{|l|}{ Age in (years) } \\
\hline$<30$ & 0.967 & 0.463 & 2.022 & 0.929 & 0.273 & 0.022 & 3.348 & 0.310 \\
\hline $30-40$ & 1.623 & 0.683 & 3.859 & 0.273 & 0.399 & 0.038 & 4.226 & 0.445 \\
\hline$>40$ & 1 & Ref. & & 0.445 & 1 & Ref. & & 0.589 \\
\hline \multicolumn{9}{|l|}{ Gender } \\
\hline Male & 1.856 & 0.955 & 3.606 & 0.068 & 1.184 & 0.197 & 7.117 & 0.853 \\
\hline Female & 1 & Ref. & & & 1 & Ref. & & \\
\hline \multicolumn{9}{|l|}{ Ethnicity } \\
\hline Omani & 0.560 & 0.163 & 1.929 & 0.358 & 0.876 & 0.171 & 4.481 & 0.873 \\
\hline Non-Omani & 1 & Ref. & & & 1 & Ref. & & \\
\hline \multicolumn{9}{|l|}{ Admission/work area } \\
\hline Medical & 0.331 & 0.101 & 1.077 & 0.066 & 0.289 & 0.027 & 3.083 & 0.304 \\
\hline Surgical & 0.435 & 0.147 & 1.288 & 0.133 & 0.167 & 0.018 & 1.579 & 0.118 \\
\hline Obstetrics and gynaecology & 1 & Ref. & & 0.185 & 1 & Ref. & & 0.275 \\
\hline Classification percentage correct & $82.3 \%$ & & & & $88.2 \%$ & & & \\
\hline 2 Log likelihood & $254.335^{\mathrm{a}}$ & & & & $66.644^{\mathrm{a}}$ & & & \\
\hline Cox \& Snell R Square & .065 & & & & .114 & & & \\
\hline Nagelkerke R Square & .107 & & & & .220 & & & \\
\hline Hosmer and Lemeshow & 1.000 & & & & 0.249 & & & \\
\hline
\end{tabular}

${ }^{\text {aOdds ratio }}$

${ }^{b} 95 \%$ confidence interval of odds ratio

${ }^{c} P$ value (level of significance) 
practice the Patient Safety Friendly Hospital Initiative (PSFHI) $[4,6]$.

It is worth stating that HCPs ranked themselves slightly higher in both quality of care and patient safety than did patients. This finding is consistent with Miranda et al. [28], who indicated that healthcare providers were more optimistic about their services. The following may be the reasons for this optimism: first, patients may not express their complaints regarding care because of cultural characteristics; second, HCPs may think that they provide high-quality care [29]. This finding was supported by Zhao et al. [30], who stated that nurses believed that they provided holistic care, while patients perceived that quality care may have interfered with their privacy and sleep duration.

The binary logistic regression analysis for this study showed an association of overall patient safety and quality of care with demographic characteristics (hospital, age, gender, ethnicity, and admission/work area). HCPs at hospital $\mathrm{B}$ rated the overall quality of care and patient safety higher than did HCPs at hospital A. This might be due to the heavier workload in hospital A because it is a specialized facility for medical and chronic cases with long durations of hospitalizations.

The findings of this study showed a significant difference in the overall quality of care among patients and HCPs in the medical department. This result matches the findings of Abuosi [31], who stated that nurses and patients had different views on quality care because they understood and characterised it differently.

This study provides meaningful insights into the perspectives of patients and HCPs on quality of care and patient safety. Such insights can be useful for current and future projects that the $\mathrm{MOH}$ is spearheading in line with the Sultanate's Health Vision 2050 [41].

\section{Strengths and limitations}

Oman has implemented quality assurance and practiced patient safety strategies at its healthcare institutions for several years, which may explain the positive findings. This should, in particular, encourage countries that have not yet implemented these strategies. However, this study has some limitations as well. First, it focused on only two variables: the overall quality of care and patient safety and their association with demographic characteristics. Second, data were collected from only three departments at two hospitals, which may affect the generalization of the study results. The response rate of both target groups, though acceptable, could have been higher [32,33]. Third, quality of care and patient safety are broad concepts that are affected by several factors and cannot be adequately explored only through selfassessment methods. An interview and focus group discussions with patients and HCPs would therefore provide more insight into this area.

\section{Conclusions}

This study has explored the perspectives of patients and HCPs on quality of care and patient safety in Oman. The results indicated that both patients and HCPs ranked quality of care and patient safety as excellent relative to magnet hospital standards. Thus, patients are satisfied with the levels of the healthcare delivery system and that they acknowledge and appreciate the healthcare services provided to them. This may also indicate that HCPs are well rounded in their core competencies and implement the appropriate quality assurance strategies and practices.

Hospital and admission/work area variables contributed to the overall quality of care and patient safety. These perspectives can be used to further improve delivery models at healthcare institutions in line with the Sultanate's Health Vision 2050.

\section{Abbreviations}

HCPs: Healthcare professionals; CoE: Council of Europe; IOM: Institute of Medicine; WHO: World Health Organization; US: United States; MOH: Ministry of Health; PSFHI: Patient Safety Friendly Hospital Initiative; RHCS: Revised Humane Caring Scale; HPCCl: Healthcare Professional Core Competency Instrument; OBG: Obstetrics and gynaecology; N: Number of participants; M: Mean; SE: Standard error; $p:$ P value; OR: Odds ratio; Cl: Confidence interval; SPSS: Statistical Package for the Social Sciences computer program

\section{Supplementary Information}

The online version contains supplementary material available at https://doi. org/10.1186/s12913-021-07152-2.

Additional file 1. STROBE Statement-Checklist of Quality of Care and Patient Safety at Healthcare Institutions in Oman: Quantitative Study of the Perspectives of Patients and Healthcare Professionals.

\section{Acknowledgements}

The authors would like to express their gratitude to the Ministry of Health, Sultanate of Oman for grant support, as well as the specialist statisticians, Docent Matti Estola, Ph.D., and Dr. Juho Kopra, Ph.D., for their contributions to the data analysis.

\section{Authors' contributions}

F.A. led the initial study conception and design, with support from T.K. and H.T. Data were collected by F.A. Data analysis and interpretation were performed by all the authors. The first draft of the manuscript and tables was written by F.A., with T.K., R.S. and H.T. providing feedback and contributing substantially to its revision. F.A., T.K. and H.T. have read and approved the final manuscript.

\section{Funding}

The first author would like to express gratitude to the Ministry of Health, Sultanate of Oman, for funding support.

\section{Availability of data and materials}

The datasets used and/or analysed during the current study are available from the corresponding author upon reasonable request. 


\section{Declarations}

\section{Ethics approval and consent to participate}

Ethical approval to conduct the study was granted by the University of Eastern Finland Committee on Research Ethics (Statement 16/2018), and permission to conduct the study in the hospitals was obtained from the MOH, Sultanate of Oman (Proposal ID: MOH/CSR/18/XXXX). All methods were performed in accordance with the relevant guidelines and regulations in the declaration. This study used data collected in December 2018 and January 2019. Informed consent was obtained from participants to use their anonymized information and all data were treated confidentially.

\section{Consent for publication}

Not applicable.

\section{Competing interests}

The authors declare that they have no competing interests.

\section{Author details}

'Department of Nursing Science, University of Eastern Finland, P.O. Box 1627, 70211 Kuopio, Finland. ${ }^{2}$ Institute of Clinical Medicine, School of Medicine, Faculty of Health Sciences, University of Eastern Finland, P.O. Box 1627, 70211 Kuopio, Finland.

Received: 21 June 2021 Accepted: 6 October 2021 Published online: 16 October 2021

\section{References}

1. Institute of Medicine. The future of nursing: leading change, advancing health. Washington, DC: The National Academies Press; 2011.

2. Salih SA, Adbelkader Reshia FA, Bashir WAH, Omar AM, Ahmed ES. Patient safety attitude and associated factos among nurses at Mansoura University Hospital: a cross sectional study. Int J of Africa Nurs Sci. 2021;14:100287. https://doi.org/10.1016/j.ijans.2021.100287.

3. World Health Organization: Patients for patient safety. 2021. https://www. who.int/patientsafety/patients for patient/en/. Accessed 11 Mar 2021.

4. Al-Mandhari A, Al-Farsi S, Al-Barwani S, Al-Salmani N, Al-Rabhi S, Al-Saidi S, et al. Developing patient safety system using WHO tool in hospitals in Oman. Int J Qual Health Care. 2018;30(6):423-8. https://doi.org/10.1093/ intqhe/mzy050.

5. Al Khamisi YN, Khan MK, Munive-Hernandez JE. Assessing quality management system at a tertiery hospital in Oman using a hybrid knowledge-based system. Int J Eng Bus Manag. 2018;10:1-13. https://doi. org/10.1177/1847979018797006.

6. Ministry of Health: Directorate General of Quality Assurance Center. 2021. https://www.moh.gov.om/en/web/directorate-quality-assurance-center/ introduction. Accessed 13 Mar 2021.

7. World Health Organization. Regional Office for the Eastern Mediterranean. Country cooperation strategy for WHO and Oman 2018-2022. Muscat: 2017. https://apps.who.int/iris/handle/10665/259861.

8. World Health Organization. World Health Statistics. 2012. https://www.who int/gho/publications/world_health_statistics/EN_WHS2012_Full.pdf. Accessed 15 April 2021.

9. Ministry of Health. Quality and Patient Safety: Health Vision 2050. Muscat: Ministry of Health; 2016.

10. Cave E. Selecting treatment options and choosing between them: delineating patient and professional autonomy in shared decision-making. Health Care Anal. 2020;28(1):4-24. https://doi.org/10.1007/s10728-019-003 84-8.

11. European Commission: Defining value in "value-based healthcare". 2019. https://ec.europa.eu/health/sites/health/files/expert_panel/docs/024_ defining-value-vbhc_en.pdf. Accessed 12 Dec 2020.

12. Konrad TR, Link CL, Shackelton RJ, Marceau LD, Knesebeck O, Siegrist J, et al. It's about time: physicians' perceptions of time constraints in primary care medical practice in three national healthcare systems. Med Care. 2010;48(2): 95-100. https://doi.org/10.1097/MLR.0b013e3181c12e6a.

13. Papp R, Borbas I, Dobos E, Bredehorst M, Jaruseviciene L, Vehko T, et al. Perceptions of quality in primary health care: perspectives of patients and professionals based on focus group discussions. BMC Fam Pract. 2014; 15(128):1-13. https://doi.org/10.1186/1471-2296-15-128.
14. Mold JW, Lawler F, Schauf KJ, Aspy CB. Does patient assessment of the quality of the primary care they receive predict subsequent outcomes?: An Oklahoma, physicians resource/research network (OKPRN) study. J Am Board Fam Med. 2012;25(4):e1-e12. https://doi.org/10.3122/jabfm.2012.04.12 0106

15. Berchtold P, Kunzi B, Busato A. Differences of the quality of care experience: the perception of patients with either network or conventional health plans. Fam Pract. 2011;28(4):406-13. https://doi.org/10.1093/fampra/cmr010.

16. Kroneman MW, Maarse $\mathrm{H}$, van der Zee J. Direct access in primary care and patient satisfaction: a European study. Health Policy. 2006;76(1):72-9. https:// doi.org/10.1016/j.healthpol.2005.05.003.

17. Perneger T. The Council of Europe recommendation rec (2006) 7 on management of patient safety and prevention of adverse events in health care. Int J Qual Health Care. 2008;20(5):305-7. https://doi.org/10.1093/ intahc/mzn034

18. Schwappach D, Frank O, Koppenberg J, Muller B, Wasserfallen J. Patient's and healthcare workers' perceptions of a patient safety advisory. Int J Qual Health Care. 2011;23(6):713-20. https://doi.org/10.1093/intqhc/mzr062.

19. Al Jabri A, Kvist T, Azimirad M, Turunen H. A systematic review of healthcare professionals' core competency instruments. Nurs Health Sci. 2021;23(1):116. https://doi.org/10.1111/nhs.12804.

20. National Centre for Statistics \& Information: Statistical yearbook. 2020. https://data.gov.om/search?query=Population. Accessed 17 Dec 2020.

21. Department of Health Information and Statistics: Annual health report. 2019. https://www.moh.gov.om/en/web/statistics/-/-2019. Accessed 11 Nov 2020.

22. Elm EV, Altman DG, Egger M, Pocock SJ, Gotzsche PC, Vandenbroucke JP. The Strengthening the reporting of observational studies in epidemiology (STROBE) statement: guidelines for reporting observational studies. Int J Surg. 2014;12(12):1495-9. https://doi.org/10.1016/j.jisu.2014.07.013.

23. Kvist T, Mantynen R, Turunen H, Partanen P, Miettinen M, Wolf G, et al. How magnetic are Finnish hospitals measured by transformational leadership and empirical quality outcomes? J Nurs Manag. 2013;21(1):152-64. https:// doi.org/10.1111/j.1365-2834.2012.01456.x.

24. Lee N, An J, Song T, Jang H, Park S. Psychometric evaluation of a patient safety competency self-evaluation tool for nursing students. J Nurs Educ. 2014;53(10):550-62. https://doi.org/10.3928/01484834-20140922-01.

25. Sastre-Fullana P, Morales-Asencio J, Sese-Abad A, Bennasar-Veny M, Fernandez-Dominguez J, Pedro-Gomez J. Advanced practice nursing competency assessment instrument (APNCAl): Clinimetric validation. PMJ Open. 2017;7(2):1-9. https://doi.org/10.1136/bmjopen-2016-013659.

26. American Nurses Credentialing Center [ANCC]. The 2019 magnet application manual: nursing excellence standards evolving with practice. J Nurs Adm. 2017:47(11):527-8. https://doi.org/10.1097/NNA. 0000000000000547.

27. Alrashdi I. Evaluation of quality of healthcare: to what extent can we rely on patient expectations and preferences. Oman Med J. 2012;27(6):448-9. https://doi.org/10.5001/omj.2012.107.

28. Miranda FJ, Chamorro A, Murillo LR, Vega J. An importance-performance analysis of primary health care services: managers vs. patients' perceptions. J Serv Manag. 2010;3(2):227.

29. Boga SM, Sayilan AA, Kersu O, Baydemir C. Perception of care quality and ethical sensitivity in surgical nurses. Nurs Ethics. 2020;27(3). https://doi.org/1 $0.1177 / 0969733020901830$.

30. Zhao SH, Akkadechanunt T, Xue XL. Quality nursing care as perceived by nurses and patients in a Chinese hospital. J Clin Nurs. 2009;18(12):1722-8. https://doi.org/10.1111/j.1365-2702.2008.02315.x.

31. Abuosi A. Patients versus healthcare providers' perceptions of quality of care: establishing the gaps for policy action. Clin Gov Int J. 2015;20(4):17082. https://doi.org/10.1108/CGIJ-03-2015-0010.

32. Hendra R, Hill A. Rethinking response rates: new evidence of little relationship between survey response rates and nonresponse bias. Eval Rev. 2019;43(5):307-30. https://doi.org/10.1177/0193841X18807719.

33. Johnson TP, Wislar JS. Response rates and nonresponse errors in surveys. JAMA. 2012;307(17):1805-6. https://doi.org/10.1001/jama.2012.3532.

\section{Publisher's Note}

Springer Nature remains neutral with regard to jurisdictional claims in published maps and institutional affiliations. 